\title{
Analisis Kelayakan Investasi Pembangunan Kembali Pasar Pahing Kedu Kabupaten Temanggung
}

\author{
Sugiyarto $^{1)}$; Edy Purwanto ${ }^{2)}$; Salis Kurniawati ${ }^{3)}$ \\ 1) , ${ }^{2)}$ Dosen Pembimbing Skripsi \\ 3) Mahasiswa Program Studi Teknik Sipil, Fakultas Teknik, Universitas Sebelas Maret \\ Jln Ir. Sutami 36A, Surakarta 57126 Telp : 0271-634524 \\ Email : saliskurniai0112130@gmail.com
}

\begin{abstract}
Population development in an area influences the provision of economic facilities in the region. One of them is the market, both traditional and modern markets. Activities that occur in the market can provide an overview of the economic conditions of the community in the area. Nowadays the existence of traditional markets is increasingly eliminated by the increasing number of modern markets, moreover with the impression of traditional markets which have always been known as dirty, smells bad, and minimum facilities, so then to maintain the existence of traditional markets the government needs to repair or rebuild traditional markets, one of them is Pabing Market, Kedu, in Temanggung Regency. But before doing the rebuilding of the market, a study was needed to analyze the magnitude of minimum value of stall selling, and then analyze the price financially feasible or not in terms of benefit cost ratio and break even point analysis during the economic life of the building of 20 years.

The results showed that the investment needed for the rebuilding project of Pahing Market, Kedu, in Temanggung Regency is $\mathrm{R} p$ 3.780.620.481,00. The minimum selling value of the stall for a 3 years installment period is Stall Type A: Rp. 4.412.891,42 / month, Stall Type B : Rp. 3.309.668,57 / month, Stall Type C : Rp. 3.309.668,57 / month, Stall Type D : Rp. 1.470.963,81 / month, and Stall Type E : Rp. 1.470.963,81 / month. Whereas for the 5 years installment period, Stall Type A : Rp 1.542.497,53 / month, Stall Type B : Rp 1.156.873,14 / month, Stall Type C : Rp 1.156.873,14 / month, Stall Type D : Rp 514.165,84 / month, and Stall Type E : Rp 514.165,84 / month. On the criteria of feasibility assessment for the economic life of a 20-year building, the benefit cost ratio of 1 is obtained, and with the analysis of break even point we know that the investment can return after 1,76 years for the installment period of 3 years, while the 5-year installment can return after 2,22 years.

This research was carried out by avoiding losses, while the Temanggung Regency Government prioritized the social economic democracy with aim of increasing the prosperity, so it is very possible that there would be a difference in determining the stall selling price.
\end{abstract}

Keywords: investment, income, outlay, selling points

\begin{abstract}
Abstrak
Perkembangan penduduk di suatu wilayah berpengaruh pada penyediaan sarana perekonomian di wilayah tersebut. Salah satunya ialah pasar, baik pasar tradisional maupun modern. Kegiatan-kegiatan yang terjadi di pasar dapat memberikan gambaran tentang kondisi perekonomian masyarakat di lingkungan tersebut. Saat ini keberadaan pasar tradisional semakin tersingkir dengan semakin bertambahnya jumlah pasar modern, ditambah pula dengan kesan pasar tradisional yang selama ini selalu dikenal kumuh, bau, dan minim fasilitas, sehingga untuk menjaga eksistensi dari pasar tradisional pemerintah perlu melakukan perbaikan atau pembangunan kembali pasar tradisional yang ada, salah satunya ialah Pasar Pahing Kedu Kabupaten Temanggung. Namun sebelum melaksanakan proyek tersebut, maka perlu diadakan penelian terlebih dahulu dengan tujuan untuk menganalisis pendapatan yang ada sesuai dengan regulasi yang berlaku untuk mengetahui besarnya nilai jual minimum kios, dan harga tersebut dianalisis layak atau tidak ditinjau dari perbandingan manfaat dan biaya (benefit cost ratio) dan analisis titik impas (break even point) selama umur ekonomis bangunan 20 tahun.

Hasil penelitian menunjukkan bahwa investasi yang diperlukan untuk proyek pembangunan kembali Pasar Pahing Desa Kedu Kabupaten Temanggung adalah sebesar Rp 3.780.620.481,00. Besarnya nilai jual minimum agar proyek tersebut layak untuk masa angsuran selama 3 tahun adalah Kios Tipe A sebesar Rp 4.412.891,42 / bulan, Kios Tipe B sebesar Rp 3.309.668,57 / bulan, Kios Tipe C sebesar Rp 3.309.668,57 / bulan, Los Tipe D sebesar Rp 1.470.963,81 / bulan,dan Los Tipe E sebesar Rp 1.470.963,81 / bulan. Sedangkan untuk masa angsuran 5 tahun adalah Kios Tipe A sebesar Rp 1.542.497,53 / bulan, Kios Tipe B sebesar Rp 1.156.873,14 / bulan, Kios Tipe C sebesar Rp 1.156.873,14 / bulan, Los Tipe D sebesar Rp 514.165,84 / bulan,dan Los Tipe E sebesar Rp 514.165,84 / bulan. Pada kriteria penilaian kelayakan selama
\end{abstract}


umur ekonomis bangunan 20 tahun didapatkan nilai benefit cost ratio sebesar 1, dan dengan analasis titik impas diketahui investasi tersebut dapat kembali setelah 1,76 tahun untuk masa angsuran selama 3 tahun, sedangkan untuk masa angsuran 5 tahun dapat kembali setelah 2,22 tahun.

Penelitian ini dilakukan dengan menghindari adanya kerugian, sedangkan pemerintah Kabupaten Temanggung lebih mengutamakan sisi sosial kemasyarakatan dan ekonomi kerakyatan dengan tujuan peningkatan kesejahteraan, sehingga sangat mungkin terjadi adanya perbedaan dalam menentukan harga jual kios.

Kata kunci : investasi, pendapatan, pengeluaran, nilai jual

\section{PENDAHULUAN}

Perkembangan penduduk di suatu wilayah berpengaruh pada penyediaan sarana perekonomian di wilayah tersebut. Salah satu sarana yang sangat dibutuhkan dalam suatu masyarakat guna memenuhi kebutuhan hidup mereka sehari-hari ialah pasar. Kegiatan-kegiatan yang terjadi di pasar dapat memberikan gambaran tentang kondisi perekonomian masyarakat di lingkungan tersebut.

Saat ini keberadaan pasar tradisional semakin tersingkir dengan semakin bertambahnya jumlah pasar modern yang dengan mudah dapat ditemukan dimana-mana. Ditambah pula dengan kesan pasar tradisional yang selama ini selalu dikenal kumuh, bau, dan minim fasilitas, sehingga semakin mengurangi keinginan masyarakat untuk berkunjung ke pasar tradisional.

Untuk menjaga eksistensi dari pasar tradisional maka pemerintah perlu mengubah kesan pasar tradisional yang telah melekat selama ini dengan melakukan perbaikan atau pembangunan kembali pasar tradisional yang ada agar suasana dan fasilitas-fasilitasnya dapat bersaing dengan pasar-pasar modern yang kini telah banyak ditemui. Salah satunya ialah dengan membangun kembali Pasar Pahing Kedu Kabupaten Temanggung yang mana kondisinya memang sudah kurang layak. Dengan demikian, diharapkan Pasar Pahing Kedu dapat bersaing dengan pasar-pasar modern.

\section{LANDASAN TEORI}

Joemanto (2008) menyatakan bahwa dalam analisis kelayakan investasi pembangunan kembali pasar beran kabupaten Ngawi dibutuhkan biaya total (investasi) sebesar Rp. 5.000.770.650,00 dan besarnya nilai jual agar proyek dikatakan layak untuk angsuran selama 3 tahun harga jual kios bagian depan Rp. 7.608.986,89/m2, kios bagian samping Rp. 6.340.822,41/m2, kios bagian belakang Rp. $5.072 .657,93 / \mathrm{m} 2$, sedangkan untuk masa angsuran selama 5 tahun harga jual kios bagian depan Rp.7.514.541,36/m2, kios bagian samping Rp. 6.262.117,80/m2 kios bagian belakang Rp. 5.009.694,24/m2. Nilai investasi tersebut untuk dapat kembali selama masa angsuran selama 3 th adalah 3,829 tahun, sedangkan untuk masa angsuran selama 5 tahun dapat kembali setelah 8,089 tahun.

Supardi (2010) menyatakan bahwa dalam analisis kelayakan investasi pembangunan kembali pasar gading kota Surakarta dibutuhkan biaya total (investasi) sebesar Rp. 8.624.100.000,00 dan besarnya nilai jual agar proyek dikatakan layak untuk angsuran selama 3 tahun harga jual kios bagian depan Rp. 3.010.796,03/bulan, kios bagian samping Rp. 2.508.996,69/bulan, kios bagianbelakang Rp. 2.007.197/bulan, sedangkan untuk masa angsuran selama 5 tahun harga jual kios bagian depan Rp.2.040.054,48/bulan, kios bagian samping Rp. 1.700.045,40/bulan kios bagian belakang Rp. 1.360.036,32/bulan. Nilai investasi dapat kembali setelah 2,73 tahun untuk masa angsuran selama 3 th dan 4,31 tahun untuk masa angsuran 5 tahun.

\section{Analisis keuangan (financial)}

Analisa keuangan (financial) berangkat dari tujuan yang umumnya dimiliki oleh perusahaan swasta yaitu berkepentingan untuk meningkatkan kekayaan perusahaan yang diukur dengan naiknya nilai saham (Imam Soeharto, 1999:109).

\section{Analisis Ekonomi}

Aspek ekonomi mengkaji manfaat dan biaya bagi masyarakat secara menyeluruh misalnya untuk keperluan negara/publik. (Imam Soeharto 1999:109)

Menurut Robert J.K (1995:22). Beberapa rumus penting yang merupakan dasar analisa ekonomi proyek yang berdasarkan/menggunakan bunga berganda (interest compound) dan metode penggadaan yang berperiode (discrete compounding) : 
1. Future Value (Harga yang akan datang)

$$
\mathrm{F}=\mathrm{P}(1+\mathrm{i})^{\mathrm{n}}
$$

atau

$$
\mathrm{F}=\mathrm{P}(\mathrm{F} / \mathrm{P}, \mathrm{i} \%, \mathrm{n})
$$

2. Present Value (Harga Sekarang)

$$
\mathrm{P}=\frac{F}{(1+i)^{n}}
$$

atau

$$
\mathrm{P}=\mathrm{F}(\mathrm{P} / \mathrm{F}, \mathrm{i} \%, \mathrm{n})
$$

3. Sinking Fund (Penanaman sejumlah uang)

$$
\mathrm{A}=\frac{F i}{(1+i)^{n}-1} \quad \text { atau }
$$

$$
A=F(A / F, i \%, n)
$$

4. Capital Recovery (Pemasukan kembali modal)

$$
\mathrm{A}=\frac{P i(1+i)^{n}}{(1+i)^{n}-1} \quad \text { atau } \quad \mathrm{A}=\mathrm{P}(\mathrm{A} / \mathrm{P}, \mathrm{i} \%, \mathrm{n})
$$

5. Future Value dari Annual

$$
\begin{array}{lll}
\mathrm{F}=\frac{A\left[(1+i)^{n}-1\right]}{i} & \text { atau } & \mathrm{F}=\mathrm{A}(\mathrm{F} / \mathrm{A}, \mathrm{i} \%, \mathrm{n}) \\
\mathrm{P}=\frac{A\left[(1+i)^{n}-1\right]}{i(1+i)^{n}} & \text { atau } & \mathrm{P}=\mathrm{A}(\mathrm{P} / \mathrm{A}, \mathrm{i} \%, \mathrm{n}) \\
\mathrm{A}=\mathrm{G}\left[\frac{1}{i}-\frac{n}{(1+i)^{n}-1}\right] & \text { atau } & \mathrm{A}=\mathrm{X}(\mathrm{A} / \mathrm{G}, \mathrm{i} \%, \mathrm{n})
\end{array}
$$

\section{Persyaratan Penentuan Retribusi}

Dalam setiap kota atau wilayah pasti mempunyai acuan atau peraturan daerah sendiri yang dibuat untuk mengatur penarikan retribusi dari pedagang, dalam penelitian ini peraturan daerah tersebut adalah Peraturan Daerah Kabupaten Temanggung Nomor 17 Tahun 2015 tentang Retribusi Pelayanan Pasar, diantaranya yaitu :

Besarnya tarif retribusi untuk kios/los adalah :

Kios kelas I : Rp 2.000/hari

Kios kelas II $\quad:$ Rp 1.500/hari

Los kelas I : Rp 1.500/hari

Los kelas II : Rp 1.000/hari

\section{Biaya Modal (Capital Cost)}

Menurut Kuiper (1971), definisi biaya modal adalah jumlah semua pengeluaran yang dibutuhkan mulai dari pra studi sampai selesai dibangun. Biaya modal dibagi menjadi dua bagian yaitu :

1. Biaya langsung (direct cost).

Biaya ini merupakan biaya yang diperlukan untuk pembangunan suatu proyek. Biaya langsung pada proyek gedung misalnya biaya pembebasan tanah dan konstruksi. Biaya tanah (land cost) berupa pengadaan tanah. Pendapatan dari suatu proyek biasa berasal dari sewa / sewa beli. Jika berasal dari sewa maka bangunan berikut tanahnya tetap menjadi pemilik pengusaha bangunan, jika berasal sewa beli maka bangunan menjadi milik penyewa dan tanah menjadi milik pengusaha bangunan atau keduanya menjadi milik penyewa setelah jangka waktu yang diperhitungkan.

2. Biaya tidak langsung (indirect cost)

Biaya ini mencakup tiga komponen yaitu :

a. Biaya kemungkinan / hal yang tidak terduga dari biaya langsung

Kemungkinan / hal yang tidak pasti ini bila dikelompokkan dapat menjadi tiga, yaitu :

1) Biaya / pengeluaran yang timbul tetapi tidak pasti

2) Biaya yang timbul namun belum terlihat

3) Biaya yang timbul akibat ditetapkannya harga pada waktu yang akan datang (misal kemungkinan adanya kenaikan harga).

Biaya ini merupakan suatu angka prosentase dari biaya langsung misal 5\%,10\% ataupun 15\% sesuai yang ditulis oleh Robert J. Kodoatie (1995). Hal ini tergantung dari pemilik dan perencana. Semakin berpengalaman pemilik atau perencana, besarnya prosentase ini lebih kecil.

b. Biaya teknik 
Biaya teknik adalah biaya untuk pembuatan desain mulai dari studi awal sampai biaya perencanaan dan pengawasan selama masa konstruksi. Biaya ini dapat ditentukan berdasarkan prosentase dari biaya langsung atau ditentukan besarnya harga yang pasti.

c. Biaya bunga

Bunga berpengaruh terhadap biaya langsung, biaya kemungkinan dan biaya teknik sehingga harus diperhitungkan selama masa konstruksi.

\section{Biaya Tahunan (Annual Cost)}

Umur ekonomi proyek dimulai setelah proyek selesai dibangun atau setelah masa konstruksi selesai. Selama pemanfaatan proyek masih diperlukan biaya sampai umur proyek selesai dan merupakan beban yang masih harus dipikul oleh pihak investor. Biaya tahunan terdiri dari :

1. Biaya operasinal dan pemeliharaan

Biaya operasional dan pemeliharaan diperlukan agar dapat memenuhi umur proyek sesuai yang direncanakan pada detail desain.

Kelompok ini terdiri dari :

1) Biaya pemeliharaan gedung

2) Biaya listrik, telepon, dan $\mathrm{AC}$

3) Pajak Bumi dan Bangunan (PBB)

4) Asuransi gedung dan peralatan

5) Biaya personal dari pengelola gedung

Menurut Hartono Poerbo (1993), proyek flat besarnya sekitar $5 \%$ dari biaya modal.

2. Biaya depresiasi

Untuk keperluan analisa pendapatan, cukup digunakan sistem garis lurus (straight line method). Beban penyusutan depresiasi dengan metode garis lurus dari satu aktiva dari tiap periode akuntansi selama masa manfaat jumlahnya sama besar kecuali ada penyusutan. (Hartono Poerbo, 1993:10)

Formula dari Metode Garis Lurus :

$$
D t=\frac{C-S}{N}
$$

Keterangan :

Dt : biaya penyusutan selama waktu dalam tahun $\mathrm{t}$

C : harga pembelian aset

$\mathrm{S} \quad$ : nilai jual-beli pada akhir usia kegunaan aset

$\mathrm{N} \quad$ : usia kegunaan aset yang diperkirakan

$\mathrm{T} \quad$ : jumlah tahun penyusutan (pemakaian waktu dari pembelian)

3. Biaya pengembalian modal

Setiap penanaman modal pasti mengharap modalnya kembali berikut keuntungan yang prosentasenya lebih tinggi dari tingkat bunga di pasaran uang atau modal, sebab setiap investasi mengandung resiko (investment risk).

Biaya pengembalian modal bisa diperoleh dengan menghitung biaya modal setelah masa konstruksi terlebih dahulu yaitu dengan rumus :

$$
\mathrm{F}=\mathrm{P}(\mathrm{F} / \mathrm{P}, \mathrm{i} \%, \mathrm{n})
$$

Dengan, $\quad$ F $\quad$ : Biaya modal setelah masa konstruksi

$$
\text { P : Biaya modal }
$$

Setelah itu, biaya pengembalian modal dapat dicari dengan menggunakan rumus :

Keterangan :

$$
\mathrm{A}=\mathrm{P}(\mathrm{A} / \mathrm{P}, \mathrm{i} \%, \mathrm{n})
$$

A : Biaya pengembalian modal per tahun

P : Perkembangan biaya modal selama masa konstruksi

i $\quad$ : Interest (bunga), yaitu besarnya suku bunga (\%)

n : Periode waktu

4. Biaya pajak

Dalam analisa proyek ini, Hartono Poerbo (1993) menyatakan besarnya pajak diperhitungkan sebesar $15 \%$ dari pendapatan kotor setelah dikurangi :

1) Pembayaran biaya operasi dan pemeliharaan gedung

2) Pembayaran modal pinjaman

3) Penyusutan gedung 


\section{Masa Konstruksi}

Untuk proyek-proyek komersil yang dibiayai dengan modal pinjaman yang dikenakan bunga meskipun proyek belum menghasilkan pendapatan, masa konstruksi diusahakan sesingkat mungkin, agar beban bunga selama masa periode sekecil-kecilnya. Kreditur umumnya memberi keringanan berupa penangguhan pokok kredit dan bunganya selama masa konstruksi (grace periode). Ada juga yang memberikan penangguhan pembayaran pokok kreditnya saja dan bunganya harus dibayar.

\section{Nilai Jual Minimum}

Untuk jenis proyek yang memberikan jasa maka biaya operasi dan pemeliharaan harus dimasukkan sesuai umur proyek yang telah direncanakan dan menjadi tanggung jawab pihak pengelola / pemilik proyek, sehingga biaya ini dimasukkan dalam unsur tambahan biaya modal (Robert J.K, 1995:59).

Nilai jual minimal dapat diperoleh dari pendapatan sama dengan pengeluaran.

Bila nilai jual minimal yang didapat lebih rendah dari pasaran nilai jual pada suatu waktu, berarti proyek sangat fisibel dalam arti mudah dipasarkan dan menarik bagi investor.

\section{Perbandingan Manfaat dan Biaya (Benefit Cost Ratio)}

Benefit Cost Ratio (BCR) digunakan untuk mengkaji kelayakan proyek yang menggambarkan besarnya resiko proyek. Rasio atau perbandingan ini harus lebih besar selisihnya terhadap satu. Makin besar selisihnya terhadap satu, makin kecil resiko proyek / resiko investasi. Penggunaannya amat dikenal dalam mengevaluasi proyek-proyek untuk kepentingan umum atau sektor publik. Dalam hal ini penekanannya ditujukan kepada manfaat (benefit) bagi kepentingan umum dan bukan kepentingan finansial perusahaan.

$$
B C R=\frac{\Sigma P V \cdot P-\Sigma P V \cdot O P-\Sigma P V \cdot B-\Sigma P V \cdot P J}{C}
$$

Dimana :

BCR : Benefit Cost Ratio yaitu Perbandingan Manfaat dan Biaya

PV.P : Nilai Sekarang Pendapatan

PV.OP : Nilai Sekarang Operasional

PV.B : Nilai Sekarang Bunga

PV.PJ : Nilai Sekarang Pajak

C : Biaya Modal

Adapun kriteria BCR akan memberikan petunjuk sebagai berikut :

BCR $>1$ usulan proyek diterima

BCR $<1$ usulan proyek ditolak

$\mathrm{BCR}=0 \mathrm{Netral}$

\section{Titik Impas (Break Even Point)}

Setiap usaha mempunyai resiko dan ketidakpastian. Dengan analisa titik impas besarnya resiko dapat diketahui dalam rangka suatu proses pemutusan. Titik impas dicapai bila keadaan usaha telah menghasilkan pendapatan yang dapat menutup semua pengeluaran.

\section{METODE PENELITIAN}

Metode yang digunakan pada penelitian ini adalah metode analisis deskriptif kuantitatif. Deskriptif kuantitatif berarti pemaparan masalah yang ada pada saat ini disertai dengan perhitungan, sedangkan analisis berarti menggunakan fakta atau informasi yang telah tersedia kemudian informasi tersebut disusun, dijelaskan, kemudian dianalisis. Metode ini melakukan analisa perhitungan investasi pembangunan Pasar Pahing Kedu Kabupaten Temanggung, sehingga diperoleh suatu hasil yang menegaskan hubungan antara variable yang dianalisa, yaitu hubungan antara volune investasi bangunan pasar dengan nilai jual dan tolak ukur finansial ekonomi lainnya.

\section{Tahap-Tahap Pelaksanaan Penelitian}

\section{Tahap I}

Tahap persiapan (Pengumpulan Data)

Tahap II

Tahap perhitungan besaran-besaran fisik teknologis gedung dan klasifikasi data yang diperlukan pada tahap I sesuai analisa tekno ekonomi. 


\section{Tahap III}

Tahap perhitungan biaya investasi total proyek.

Tahap IV

Tahap perhitungan estimasi pendapatan dan pengeluaran proyek.

Tahap V

Tahap estimasi perhitungan nilai jual minimal.

Tahap VI

Tahap analisa kelayakan investasi.

\section{HASIL DAN PEMBAHASAN}

Hasil analisis yang dilakukan di bahas sebagai berikut:

1. Besarnya nilai investasi yang dikeluarkan untuk pembangunan kembali Pasar Pahing Desa Kedu Kabupaten Temanggung sebesar Rp 3.780.620.481,00.

2. Perbedaan harga jual kios/los per bulan dengan nilai jual per $\mathrm{m}^{2}$ dianalisis dengan tanpa memperhitungkan biaya tanah untuk masa pengembalian selama 3 tahun dan 5 tahun jika dibandingkan dengan harga jual per bulan yang menjadi ketetapan dari Pemerintah Kabupaten Temanggung dapat dilihat pada Tabel 1 di bawah ini :

Tabel 1 Perbandingan harga jual per $\mathrm{m}^{2}$ dengan masa pengembalian kredit investasi selama 3 tahun dan 5 tahun

\begin{tabular}{|c|c|c|c|}
\hline \multirow{3}{*}{$\begin{array}{l}\text { Jenis } \\
\text { Bangunan }\end{array}$} & \multirow{2}{*}{\multicolumn{2}{|c|}{$\begin{array}{c}\text { Harga Jual Bangunan dengan Perbedaan Masa } \\
\text { Angsuran }\end{array}$}} & \multirow{3}{*}{$\begin{array}{c}\text { Ketetapan } \\
\text { Pemerintah } \\
\text { Kabupaten } \\
\text { Temanggung }\end{array}$} \\
\hline & & & \\
\hline & $\begin{array}{c}3 \text { Tahun } \\
\left(\operatorname{Rp} 367.740,95 / \mathrm{m}^{2}\right)\end{array}$ & $\begin{array}{c}5 \text { Tahun } \\
\left(\mathrm{Rp} 128.541,46 / \mathrm{m}^{2}\right)\end{array}$ & \\
\hline Kios Tipe A & Rp 4.412.891,42 & Rp 1.542.497,53 & Rp $1.100 .000,00$ \\
\hline Kios Tip & Rp 3.309.668,57 & $6.873,14$ & $.000,00$ \\
\hline Kios Tipe C & Rp 3.309.668,57 & Rp 1.156.873,14 & Rp 500.000,00 \\
\hline Los Tipe D & Rp 1.470.963,81 & Rp 514.165,84 & Rp $150.000,00$ \\
\hline Los Tipe E & Rp $1.470 .963,81$ & Rp 514.165,84 & Rp $200.000,00$ \\
\hline
\end{tabular}

3. Perbandingan nilai manfaat dan biaya sebagai kriteria penilaian investasi dapat dilihat pada Tabel 2 di bawah ini :

Tabel 2 Perbandingan kriteria kelayakan investasi metode Benefit Cost Ratio (BCR) dengan masa pengembalian kredit investasi selama 3 tahun dan 5 tahun

\begin{tabular}{ccc}
$\begin{array}{c}\text { Masa } \\
\text { Pengembalian } \\
\text { Kredit Investasi }\end{array}$ & $\begin{array}{c}\text { BCR dengan harga jual kios } \\
\text { berdasarkan nilai jual } \\
\text { minimum kios }\end{array}$ & $\begin{array}{c}\text { BCR dengan harga jual kios } \\
\text { berdasarkan ketetapan } \\
\text { Pemerintah Kabupaten } \\
\text { Temanggung }\end{array}$ \\
\hline 3 tahun & 1 & 0,16 \\
5 tahun & 1 & 0,25 \\
\hline
\end{tabular}

Pada tabel tersebut dapat dilihat nilai BCR untuk harga jual kios berdasarkan nilai jual minimum kios adalah sama dengan 1, yang berarti proyek layak untuk dilaksanakan. Sedangkan untuk harga jual kios berdasarkan ketetapan Pemerintah Kabupaten Temanggung nilainya kurang dari 1 yang berarti proyek tersebut tidak layak untuk dilaksanakan. Namun nilai BCR untuk harga jual berdasarkan ketetapan Pemerintah Kabupaten Temanggung yang tidak memenuhi kriteria kelayakan investasi tersebut dapat diabaikan dan proyek tetap dapat dilaksanakan.

Hal tersebut dapat terjadi disebabkan oleh adanya perbedaan orientasi dalam perhitungan antara analisis ekonomi teknik dalam penelitian dan Pemerintah Kabupaten Temanggung. Hasil analisa perhitungan menggunakan analisis investasi murni untuk menghindari kerugian, sedangkan Pemerintah Kabupaten Temanggung lebih mengutamakan sisi social kemasyarakatan dan ekonomi kerakyatan dengan tujuan peningkatan kesejahteraan rakyat dan peningkatan taraf hidup masyarakat.

4. Dari hasil analisis menggunakan metode Break Even Point, diketahui bahwa nilai investasi dapat kembali dalam waktu 1,76 tahun untuk masa angsuran selama 3 tahun, dan 2,22 tahun untuk masa angsuran selama 5 tahun. 


\section{KESIMPULAN DAN SARAN}

\section{Kesimpulan}

Dari analisis dan pembahasan yang telah dilakukan dapat diambil kesimpulan sebagai berikut:

1. Investasi yang diperlukan untuk proyek pembangunan kembali Pasar Pahing Desa Kedu Kabupaten Temanggung adalah sebesar Rp 3.780.620.481,00.

2. Besarnya nilai jual minimum agar proyek tersebut layak untuk masa angsuran selama 3 tahun adalah Kios Tipe A sebesar Rp 4.412.891,42 / bulan, Kios Tipe B sebesar Rp 3.309.668,57 / bulan, Kios Tipe C sebesar Rp 3.309.668,57 / bulan, Los Tipe D sebesar Rp 1.470.963,81 / bulan,dan Los Tipe E sebesar Rp 1.470.963,81 / bulan. Sedangkan untuk masa angsuran 5 tahun adalah Kios Tipe A sebesar Rp 1.542.497,53 / bulan, Kios Tipe B sebesar Rp 1.156.873,14 / bulan, Kios Tipe C sebesar Rp 1.156.873,14 / bulan, Los Tipe D sebesar Rp 514.165,84 / bulan,dan Los Tipe E sebesar Rp 514.165,84 / bulan.

3. Investasi yang diperlukan tersebut dapat kembali setelah 1,76 tahun untuk masa angsuran selama 3 tahun, sedangkan untuk masa angsuran 5 tahun dapat kembali setelah 2,22 tahun.

\section{Saran}

Agar penelitian ini dapat bermanfaat, khususnya untuk penelitian-penelitian selanjutnya, maka penulis memberikan saran sebagai berikut:

1. Pengumpulan data untuk penelitian dari pihak-pihak yang terkait diusahakan selengkap-lengkapnya, sehingga variable yang akan dianalisa lebih mendekati kenyataan di lapangan.

2. Lakukan analisa tanpa memperhitungkan biaya pengembalian modal, sehingga hasilnya akan lebih mendekati kenyataan di lapangan.

\section{REFERENSI}

Anonim. 2015. Peraturan Daerah Kabupaten Temanggung Nomor 17 Tabun 2015 Tentang Perubahan Atas Peraturan Daerah Kabupaten Temanggung Nomor 13 Tabun 2012 Tentang Retribusi Pelayanan Pasar. Pemerintah Daerah Kabupaten Temanggung : Temanggung.

Anonim. 2018. Buku Panduan Penulisan, Tatalaksana, dan Ujian Akademik Tugas Akbir/Skripsi serta Magang $(K K M) / K P$. Program Studi Teknik Sipil Fakultas Teknik Universitas Sebelas Maret Surakarta : Surakarta. Fitzgerald. 1978. Public Sector Investment Planning for Developing Countries. Macmillan : London. Hartono Poerbo. 1993. Tekno Ekonomi Bangunan Bertingkat Banyak. Djambatan : Jakarta. Imam Soeharto. 1995. Manajemen Proyek dari Konseptual Sampai Operasional. Erlangga : Jakarta. Joemanto. 2008. Analisis Kelayakan Investasi Pembangunan Pasar Beran Kabupaten Ngawi. Skripsi : Jurusan Teknik Sipil Fakultas Teknik, Universitas Sebelas Maret Surakarta.

Kadariyah.1978. Ekonomi Perencanaan.Lembaga Penerbit Fakultas Ekonomi Universitas Inesia : Jakarta.

Kuiper, Edward. 1971. Water Resources Project Economics. Butterworths : London.

Robert J. K. 1995. Analisa Ekonomi Teknik. Andi Offset : Yogyakarta.

Rokhmat Syaeful Akbar. 2014. Analisis Kelayakan Ekonomi Pembangunan Kembali Pasar Turisari Kota Surakarta. Skripsi : Jurusan Teknik Sipil Fakultas Teknik, Universitas Sebelas Maret Surakarta.

Salim Basalamah. 1988. Penilaian Kelayakan Rencana Penanaman Modal. Gadjah Mada University Press : Yogyakarta.

Suad Husnan, Suwarsono. 1993. Studi Kelayakan Proyek Konsep, Teknik, dan Penyusunan Laporan. Unit Penerbit dan Percetakan AMPYKPN : Yogyakarta.

Supardi. 2010. Analisis Kelayakan Investasi Pembangunan Kembali Pasar Gading Kota Surakarta. Skripsi : Jurusan Teknik Sipil Fakultas Teknik Universitas Sebelas Maret Surakarta.

Supriyadi. 2013. Perencanaan Site Plan dan Studi Kelayakan Investasi Pada Perumahan Pondok Permata Hijau Desa Wirun Kecamatan Mojolaban. Skripsi : Jurusan Teknik Sipil Fakultas Teknik, Universitas Sebelas Maret Surakarta.

Ucang Sukriswanto. 2012. Analisis Kelayakan Revitalisasi Pasar Umum Gubug Kabupaten Grobogan. Tesis : Program Magister Teknik Sipil, Universitas Diponegoro Semarang.

Van Horne, James C. and John M. Wachowicz. 1981. Fundamental Of Financial Management. Prentice Hall International : New Jersey. 